\title{
A case of severe, unexplained breathlessness
}

\section{J Werring, J E Head, M Clee, M Chowdhury}

\section{Answers on $p 665$.}

A 58 year old man presented with progressive dyspnoea on walking over several weeks. On lying down, he became more dyspnoeic; sitting up brought immediate relief. A few days later he noted severe discomfort over the lateral aspect of his right arm and shoulder associated with numbness, followed by weakness when attempting to raise the arm. He was a builder, and had previously been exposed to asbestos, but was a non-smoker. There was no previous medical history of note.

On examination there was no cyanosis, peripheral oedema, clubbing, or lymphadenopathy. The jugular venous pressure was not elevated; pulse was 87 beats/min, with normal heart sounds. His blood pressure was 143/ $66 \mathrm{~mm} \mathrm{Hg}$. He was unable to lie flat due to breathlessness, but in the sitting position was in little distress, with a respiratory rate of 15 breaths/ min. Auscultation of the chest revealed bilateral basal crepitations. Neurological examination revealed minimal wasting of the right deltoid, and winging of the right scapula (fig IA and (B). Shoulder abduction was slightly weak on the right (Medical Research Council grade 4/5). Power was otherwise full in all groups in the upper and lower limbs. Reflexes and sensory testing were normal. Paradoxical inward motion of the abdmen on inspiration was observed. In view of the crepitations a trial of bumetanide $2 \mathrm{mg}$ was given intravenously with no improvement in dyspnoea.

Full blood count, urea and electrolytes, corrected calcium, liver function tests, creatine kinase, thyroid stimulating hormone, serum angiotensin converting enzyme, C-reactive protein, and erythrocyte sedimentation rate were all normal. Chest radiography showed bilateral prominent pulmonary arteries and small lung fields. Arterial blood gases revealed a $\mathrm{pH}$ of 7.40 , oxygen pressure of $8.70 \mathrm{kPa}$, and carbon dioxide pressure of $4.59 \mathrm{kPa}$. Lung function tests demonstrated forced expiratory volume in one second $\left(\mathrm{FEV}_{1}\right) 1.23$ litres and forced vital capacity (FVC) 1.58 litres (sitting), FEV $_{1}$ 0.45 litres and FVC 0.49 litres (lying). A ventilation-perfusion scan, electrocardiogram, and echocardiography were normal. A spiral computed tomogram of the chest showed raised hemidiaphragms and no intrathoracic mass. A tensilon test was negative.

\section{QUESTIONS}

(1) What is the mechanism of this patient's breathlessness and how would you confirm this?

(2) What is the likely clinical diagnosis. How would you try to establish this?

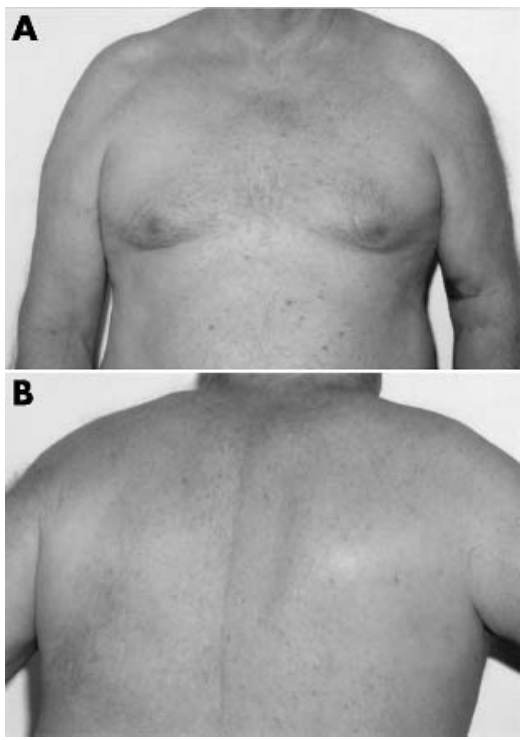

Figure 1 (A) Note subtle wasting of the right deltoid muscle. (B) The patient is pushing his arms against a wall; note subtle winging of the right scapula (photos published with patient's permission).

(3) What is the treatment and prognosis for this patient?

Postgrad Med J 2003;79:662

\section{Authors' affiliations}

D J Werring, Institute of Neurology, Queen Square, London

J E Head, M Chowdhury, Hurstwood Park Neurological Centre, Haywards Heath, West Sussex

M Clee, Conquest Hospital, St Leonards-onSea, East Sussex

Correspondence to: Dr David J Werring, National Hospital for Neurology and Neurosurgery, Queen Square, London WCIN 3BG, UK; david.werring@ukonline.co.uk

Submitted 20 October 2002

Accepted 9 January 2003

recurrence in 1977, she had been started on long term carbimazole treatment. On presentation, the patient had a moderate sized goitre and signs of mild, inactive ophthalmopathy. She was euthyroid on $5 \mathrm{mg}$ of carbimazole, which was withdrawn for seven days and a standard radioactive iodine (RAI) dose of $550 \mathrm{MBq}$ was administered. Carbimazole was not restarted after RAI as per the policy of the department. Seven days after RAI, the patient had to be hospitalised with complaints of palpitation, marked anxiety, agitation and profuse perspiration, a regular tachycardia of 130 beats/min, blood pressure of $150 / 60 \mathrm{~mm} \mathrm{Hg}$, and presented for definitive treatment of hyperthyroidism secondary to Graves' disease. In 1970 she had undergone subtotal thyroidectomy for the first episode of hyperthyroidism but after a 
pyrexia of $39^{\circ} \mathrm{C}$. White cell count was normal, blood and urine cultures were negative, and chest radiography was normal. Thyroid function test result showed a free thyroxine concentration of $90 \mathrm{pmol} / \mathrm{l}$ (normal range 10-22 pmol/l), free triiodothyronine $32 \mathrm{pmol} / \mathrm{l} \quad(2.5-5.5 \mathrm{pmol} / \mathrm{l}), \quad$ and thyroid stimulating hormone $<0.01$ (0.5-4.0 mU/l).

\section{QUESTIONS}

(1) What is the diagnosis and how frequently is this condition encountered?

(2) What is the mechanism and what are the criteria for diagnosis of this condition?

(3) How is this condition managed and how can one prevent it?

Postgrad Med J 2003;79:662-663

\section{Authors' affiliations}

H N Buch, H Kumar, T E T West, Department of Endocrinology, Princess Royal Hospital, Telford

Correspondence to: Dr H N Buch, Diabetes Centre, New Cross Hospital, Wolverhampton WV10 0QP, UK; sharun@btinternet.com

Submitted 8 December 2002

Accepted 20 January 2003

\section{Readers' favourite}

\section{Top 10}

Click on the "Top 10" button on the homepage to see which are the best read articles each month

www.postgradmedj.com 